\title{
Current panorama of temporomandibular disorders' field in Brazil
}

\author{
Naila Aparecida de Godoi MACHADO, Fernanda Ferruzzi LIMA, Paulo César Rodrigues CONTI
}

Department of Prosthodontics, Bauru School of Dentistry, Bauru, SP, Brazil.

Corresponding address: Paulo César Rodrigues Conti - Faculdade de Odontologia de Bauru - USP - Departamento de Prótese - Al. Octávio Pinheiro Brisolla, 9-75 - 17012-901 - Vila Universitária - Bauru - SP, Brazil - Phone: +55 1432358340 - e-mail: pcconti@fob.usp.br

Submitted: September 19, 2013 - Modification: January 20, 2014 - Accepted: March 2, 2014

\section{ABSTRACT}

Tn 2012, the recognition of the specialty of Temporomandibular Disorders and Orofacial 1 Pain completed ten years. Given this scenario, it is extremely important to track the current situation of this field of knowledge in Brazil, specifically in the area of research and training. We hope to discuss the importance of the recognition of this specialty and the inclusion of these subjects in undergraduate programs in Dentistry. Objective: The objective of this study is to perform a bibliometric survey of researches regarding Temporomandibular Disorders and Orofacial Pain conducted in the country, determine the number of specialization courses in Orofacial Pain and the number of specialists in the field. Methods: The bibliometric survey was conducted based on the Dissertations Portal of Coordination for the Improvement of Higher Education Personnel (CAPES) and on PubMed. The panorama of the field of Orofacial Pain and Temporomandibular disorders in Brazil was determined by searching on the website of the Brazilian Council of Dentistry. Results: We found 731 theses and dissertations with Temporomandibular Disorders and Orofacial Pain as the main subjects; 81 accredited/recognized Courses on Orofacial Pain and Temporomandibular Dysfunction completed; 8 accredited/recognized Specialization Courses on Orofacial Pain and Temporomandibular Dysfunction still in progress, and 1,064 registered specialists in Orofacial Pain and Temporomandibular Dysfunction in the Brazilian Council of Dentistry. Search in the PUBMED database yielded 576 articles published with the participation of Brazilian researchers as first authors and/or co-authors in the period from 2000 to 2013. From this amount, only 5 were published in Portuguese, while all the others were published in English. We can also notice that the number of published articles increases over time. Conclusion: The number of researches related to temporomandibular disorders has increased over the last ten years, as well as the number of specialization courses and the number of specialists, which represents a major breakthrough for this field of knowledge.

Keywords: Temporomandibular joint dysfunction syndrome. Facial pain. Education.

\section{INTRODUCTION}

The interest in the teaching of orofacial pain and TMDs issue in scientific literature is reported since the seventies ${ }^{3}$. Since then, considerable advances in this subject were observed, but they are still far from what can be considered ideal. Only few universities offer in their graduation curricular program the subject or a graduate program in orofacial pain and TMDs, either as an elective or as a compulsory ${ }^{2}$. This deficit implies in losses in the professional training of the dentist, who often feels disqualified to deal with TMD/orofacial pain patients ${ }^{7}$. Currently, there is accreditation for Advanced General Dentistry Education Programs in Orofacial Pain, and initiatives have been implemented to encourage institutions to embrace new interprofessional models ${ }^{8}$. The interprofessional nature of this field makes it difficult to establish the role of the dentist, which results in important implications for the whole process of teaching, research and clinical care.

Temporomandibular disorders (TMD) can be defined as a series of signs and symptoms involving the temporomandibular joint (TMJ), masticatory 
muscles, or both ${ }^{12,13}$. Historically, TMDs were often associated with the study of occlusion; however, this association has been increasingly questioned by the current scientific advances ${ }^{1,16}$. Therefore, the study of TMDs has ceased to be seen as traditional Dentistry and focused on an interdisciplinary involvement with other areas of health for the management of patients in a biopsychosocial paradigm.

Within the context of Dentistry, it is essential that dentists may be able to recognize, evaluate and manage patients with TMDs. Although the disorders present as highly prevalent in the general population ${ }^{10}$, for many years this field of knowledge remained a gray area in Dentistry, full of controversies and poorly discussed and taught in the academic milieu ${ }^{9,11,14,15}$.

In Brazil, specifically, the year of 2002 represents a milestone in the recognition of the specialty of Temporomandibular Disorders and Orofacial Pain (TMD/OP). This recognition led to greater technical and scientific improvement by the dentists and contributed in raising the level of knowledge of the area. Thus, this increased capacity comes to reflect directly in teaching and research, disseminating scientific knowledge and increasing the number of people involved with the specialty.

Considering that TMD/OP was recognized as a dental specialty over a decade ago, it is extremely important to trace the current situation of the field of Temporomandibular Disorders in Brazil, specifically in the areas of research and training. The objective of this study was to perform a bibliometric survey to investigate the scientific works on TMD produced in the country, determine the number of specialization courses on TMD and Orofacial Pain and the number of specialists in the area. By describing this panorama, we hope to discuss the importance of the recognition of this specialty and the inclusion of these subjects in undergraduate programs in Dentistry.

\section{METHODOLOGY}

This study can be divided in three stages: bibliometric survey in the Theses Database of Coordination for the Improvement of Higher Education Personnel (CAPES); survey on the involvement of Brazilian researchers in the publication of articles indexed by PubMed; and panorama of TMD/OP field in Brazil.

\section{Bibliometric Survey in the CAPES Theses Database}

The bibliometric survey was conducted by means of a careful search in the Theses Database of Coordination for the Improvement of Higher Education Personnel (CAPES) (http:// capesdw.capes.gov.br). We adopted the word "temporomandibular" as the search term, and the search was delimited to the period from 2000 to 2012. Unfortunately, information about the year of 2013 was not available at the time of the submission of this manuscript. For each result of the search conducted on the CAPES portal, we collected the following information:

\section{Type of scientific work}

The works registered on the CAPES database are required in order to be a candidate for $\mathrm{a} \mathrm{PhD}$ or a Master's degree, therefore they could be Doctoral Theses, Master's Dissertations or Professional Master's Dissertations. According to CAPES, the Professional Master's programs are subjected to the same criteria as the Academic Master's programs and, additionally, emphasize studies and techniques aimed at professional performance ${ }^{4}$. State of Brazil where the scientific work was performed.

\section{Field of knowledge}

The works were classified according to the following fields of knowledge: Dental Sciences, Medical Sciences, Basic Sciences, and Other.

Thematic classification of the work, subdivided into:

1- Diagnosis

2- Intervention

3- Epidemiology

4- Experimental

5- Associated Themes (when the research is related to two or more themes, for instance, diagnosis an intervention)

Data were independently collected by the authors FFL and NAGM. Discrepancies were discussed in a final revision with all the authors.

\section{Participation of Brazilian researchers in the publication of articles indexed to PubMed}

Additionally, the authors FFL and NAGM carried out a thorough search in the PubMed database to verify the participation of Brazilian researchers in the publication of scientific articles indexed to this basis. The search terms used were: "temporomandibular" and "Brazil". For each result, we confirmed the participation of Brazilian researchers either as first author or co-author of the study. Discrepancies were discussed in a final revision with all the authors.

Overview of the specialty of Temporomandibular Dysfunction and Orofacial Pain in Brazil

To determine the number of specialization courses and the number of specialists in Temporomandibular Disorders and Orofacial Pain in Brazil, a survey was conducted on the website of Federal Council of Dentistry (CFO), a Brazilian agency responsible for the regulation of specialized courses and specialist 
licenses in Brazil. The survey was conducted on the website (http://cfo.org.b), accessed on 01/15/2014 by the author NAGM.

\section{RESULTS}

Bibliometric Survey in the CAPES Theses Database

According to the bibliometric survey on the CAPES Portal, 731 scientific works were registered with TMD/OP as the main subject. From this total, 421 were Master 's theses, 195 were Doctoral theses

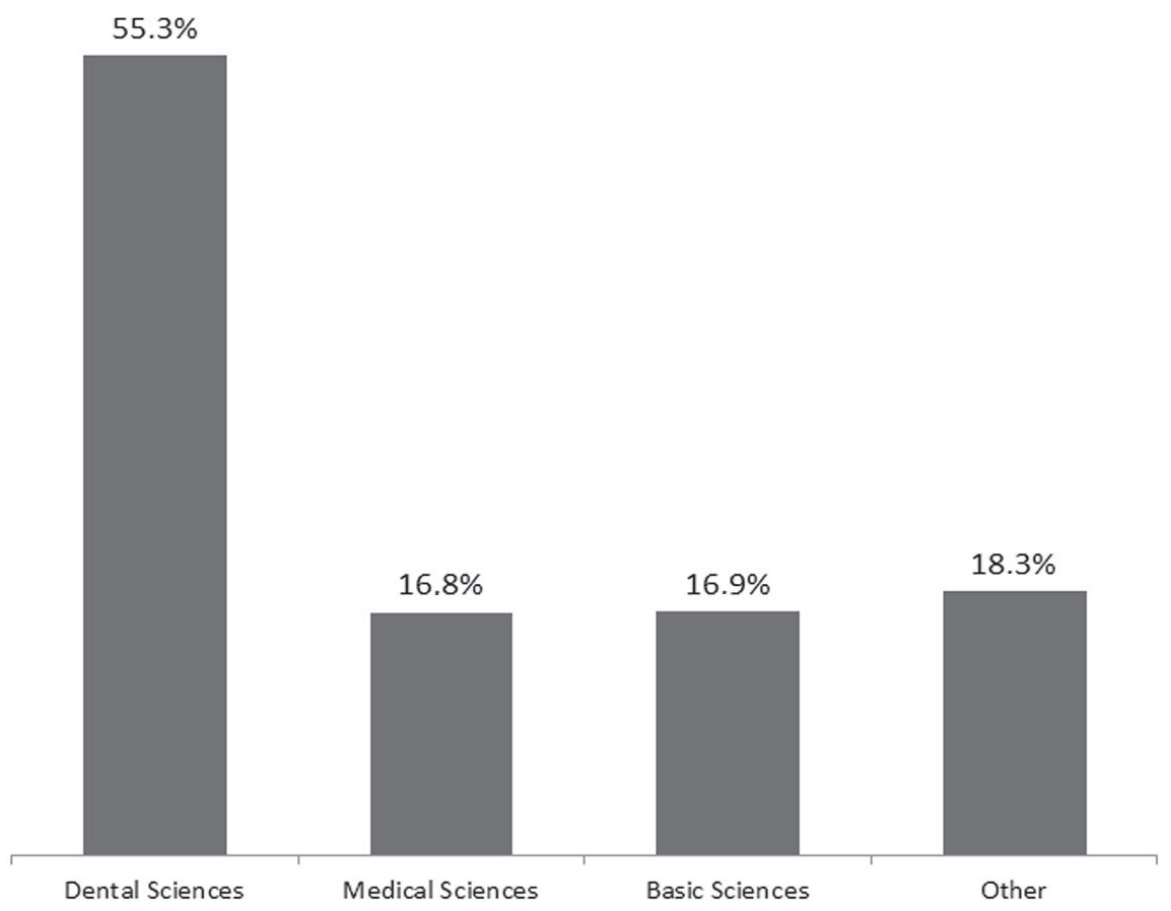

Figure 1- Distribution of scientific works available in CAPES Theses Database according to field of knowledge from 2001 to 2012

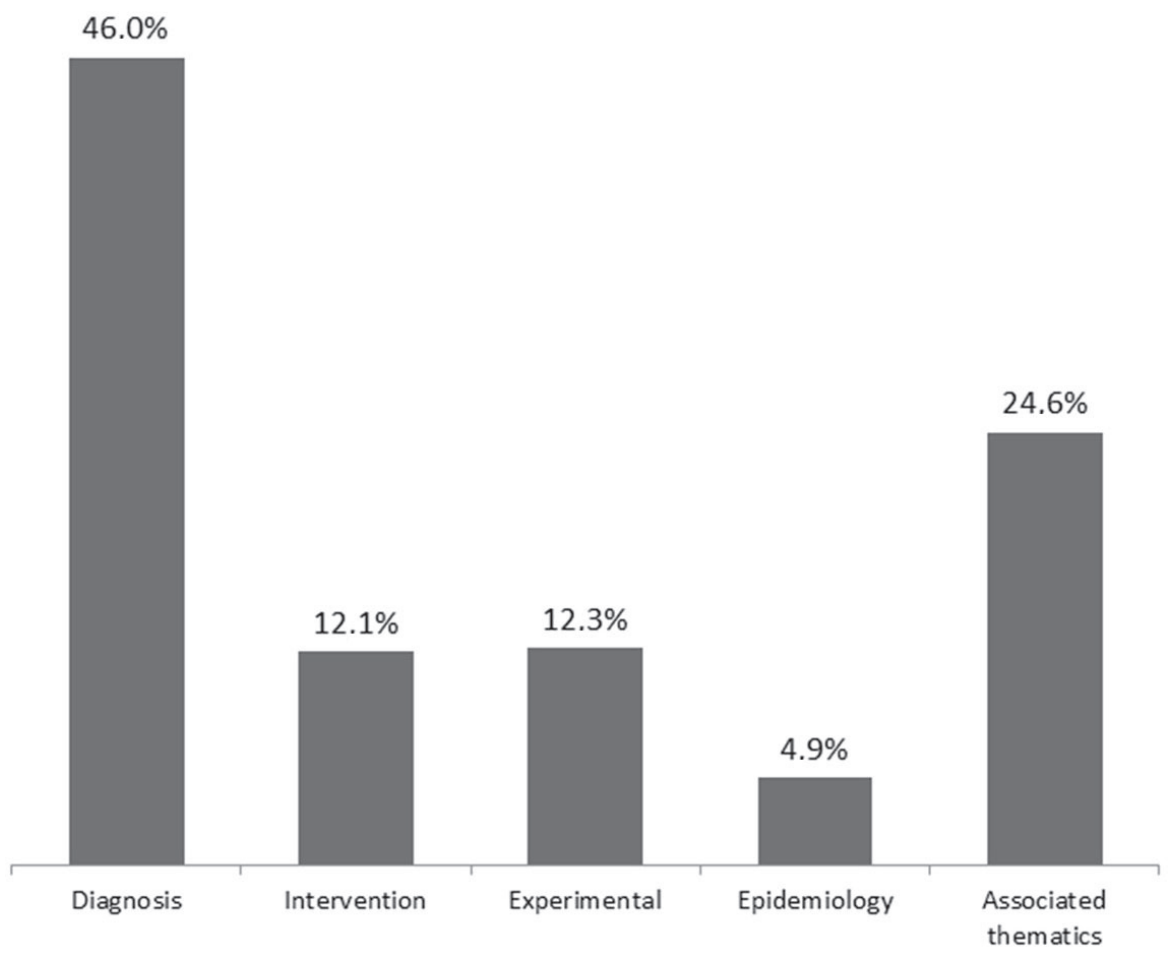

Figure 2- Thematic approaches of scientific works registered in CAPES Theses Database from 2001 to 2012 
and 115 were Professional Master's theses.

Regarding the state where the scientific works were performed, we found that $73 \%$ were from the state of São Paulo, 5\% from Minas Gerais, 4\% from Rio de Janeiro, 4\% from Rio Grande do Sul, 4\% from Paraíba, and $10 \%$ from other Brazilian states.

The information regarding the field of knowledge is shown in Figure 1. Scientific works related to Psychology.

The thematic approaches found in the CAPES Theses Database are shown in Figure 2.

\section{Participation of Brazilian researchers in published articles - PubMed}

Search in the PubMed database yielded 576 articles published with the participation of Brazilian researchers as first authors and/or co-authors in the period from 2000 to 2013. From this amount, only 5 were published in Portuguese, while all the others were published in English. We can also notice that the number of published articles increases over time.

Current panorama of the specialty in Brazil Search on the Federal Council of Dentistry (CFO) website found that until January 2014 there were:

- 254,380 registered dentists in Brazil;

- 111 accredited/recognized Specialization Courses in Orofacial Pain and Temporomandibular Disorder concluded;

- 8 accredited/recognized Specialization Courses in Orofacial Pain and Temporomandibular Disorder in progress;

- 1,064 registered specialists in Temporomandibular Disorders and Orofacial pain in Brazil.

\section{DISCUSSION}

The control of temporomandibular disorders and orofacial pain is a complex issue that requires the performance of professionals who demonstrate expertise capable of directing the diagnosis and appropriate treatment ${ }^{5,19}$. Some studies have shown the great deficiency of education in the field of TMD/ OP leading to frequent discussions on strategies for curricular restructuring and search for alternatives that Disorders and Orofacial Pain as a specialty represents an important advance in general. A specialist should be a licensed professional who has acquired special knowledge about a particular subject through study and/or experience. According to the resolution of the Federal Council of Dentistry, the specialty of Temporomandibular Disorders and Orofacial Pain can be defined as the specialty that aims to promote and develop scientific knowledge for better understanding of the diagnosis and treatment of pain and disorders of the masticatory system, orofacial region and related structures.

The Orofacial Pain specialist is responsible for diagnosing and treating patients with pain that is often chronic, multifactorial and complex. Failure in understanding the mechanisms of pain can lead to delayed diagnosis and/or incorrect, inaccurate treatments, which are ineffective or even harmful. Thus, it is the responsibility of Orofacial Pain specialist to accurately diagnose the causes of pain and decide whether treatment procedures may include dental, medical interrelated areas, counseling or even a combination of all these treatment approaches ${ }^{6}$.

Temporomandibular disorders represent a segment of Orofacial Pain. Initially, this study used the term "orofacial pain" as search term; however, the results were inconclusive. Thus, we chose to use the term "temporomandibular" for the following reasons: (1) To perform a comprehensive search, since MeSH terms "temporomandibular joint" or "temporomandibular joint dysfunctions syndrome" could limit the results to research works related only to the temporomandibular joint or only to a disease-related scenario. (2) To facilitate the search, due to the similarity of the spelling in both English and Portuguese languages, we could cluster the scientific works retrieved in a unique result. Despite the limitation of restricting the evaluation to TMD and not encompassing other forms of orofacial pain, the results provide a clear and detailed discussion of the TMD area specifically.

CAPES Theses Database is an important channel of access to knowledge production specifically aimed at disseminating information on theses and dissertations produced in Brazilian universities since 1987. Annually, this database is updated based on new information submitted by graduate programs in the country. CAPES Theses Database still has some structural limitations, for example: information about the year of 2013 was not available until the submission of this manuscript. However, this database is an important tool for open access dissemination of results of academic research, contributing for greater visibility of the work carried out in the country.

When considering scientific works registered in CAPES Theses Database, we observed that, from 2000 to 2013, the total number of registered works doubled. The reasons for this increase can be attributed to several factors such as the recognition of the specialty associated with increased interest of the dental class in the study of TMD, greater dissemination of graduate programs in the country, government incentives for research activities, among other factors.

Despite national policies to encourage the teaching and research, there is a notable disparity between the performance of research and production of scientific knowledge among the different Brazilian states, which suggests a need for reassessment of 
current policies and government action to improve this situation. The Southeast Region of the country accounted for more than $82 \%$ of CAPES Theses Database, while the Northern Region under $2 \%$. Santos, et al. ${ }^{17}$ (2009) also emphasized the highest concentration of scientific research in the Southeast region of the country and especially in the state of São Paulo, with the largest number of colleges and graduate programs.

Regarding the fields of knowledge involved in research activities related to TMD, greater participation of graduate programs on Dentistry was expected, considering that Dentistry is the area of health that has been the most devoted to the subject. Within the interdisciplinary context, cooperation of other academic areas such as Basic Sciences and Medical Sciences is increasingly required, contributing to a better understanding of TMD in view of its multidisciplinary nature. Research in the Medical and Basic Sciences have shown that many patients with temporomandibular disorders present structural and generalized symptoms such as mood disorder, generalized pain and significant systemic changes. Thus, Dentistry has taken a leadership role in healthcare in order to solve the problems in the area of TMD ${ }^{18}$, though its performance is not unique and distinct, requires the involvement of other groups of health professionals, including physicians, pharmacists, psychologists, physiotherapists, occupational therapists and speech therapists.

Another important point relates to the greatest achievement of clinical research involving diagnostic parameters, which can be attributed to the ease of conducting this relatively short term studies when compared to other modalities involving thematic treatment, etiology and epidemiology. Another reason for prioritizing this approach is associated to the possibility of performing methodologies with the fewest bias, greater availability of sampling and the need for less costly resources.

From a scientific point of view, we had significant changes in publishing articles due to the increase in the amount of online publications and Open Access journals, new funding policies, and also to the fact that universities increasingly require the participation of their teachers in research activities. The considerable growth in the number of articles published from 2000 to 2009 with the participation of Brazilian researchers as authors / co-authors can be attributed to the increasing interest of the dental community in the field of TMD and also to the CAPES policy of prioritizing the publication of articles when evaluating the scientific quality of graduate programs. This growth can also be attributed to the spread of postgraduate programs all over the country, the establishment of research groups, the great number of qualified researchers and the consolidation of scientific production. With the expansion of scientific and human resources training through postgraduate studies, there was a significant rise in demand for resources for funding research projects and grants for research productivity, as well as application of post-doctoral and PhD scholarships abroad ${ }^{20}$. On the other hand, the slight decline observed in the participation of Brazilian researchers in articles published between 2009 and 2011 can be attributed to a greater demand for quality on the part of journals for publishing the papers.

In 2012, the Brazilian Society of Temporomandibular Disorders and Orofacial Pain was founded, representing a milestone which will favor the systematization and dissemination of practice, teaching and research in this specialty in Brazil. We expect this Society can promote the enrichment and integration of teaching programs in Temporomandibular Disorders/Orofacial Pain with related subjects and professions. This society will be responsible for providing information and recommendations related to the diagnosis and treatment of TMD/OP, not only to specialists but also to general practioners and, thus, assist the dentists in offering primary care for patients affected by these conditions.

Given the rapidly changing demography of populations worldwide, dental professionals of the future need to be able to meet the challenge posed by the evolving landscape in health care needs. According to the latest demographic data from the Brazilian Institute of Geography and Statistics (IBGE) for the year 2012, Brazil has 199.3 million inhabitants. Considering the number of inhabitants in the country and the high prevalence of orofacial pain and TMD, we can say the number of specialists in the field is small. We have to point that to be a specialist in Brazil you must complete a specialization course. It is necessary to fit the new educational realities to the population needs, to develop guidelines for the expansion of theoretical and practical knowledge in the care of patients with orofacial pain and TMD. We suggest extending the specialization titles to highly qualified professionals in the fields, like researchers with several works published in the area.

Considering it is a problem with high occurrence among the population and the loss caused (financial onus, the patient suffer), the temporomandibular disorders demand the dental community's special attention in order to provide better physical, social and emotional welfare to TMD patients. Although a large number of people suffer from orofacial pain or temporomandibular disorders, Dentistry has not developed adequate educational guidelines for dealing with this problem. Thus, recognition of specialty in the area will contribute 
to the development of a scientifically-supported knowledge base for improved understanding of the diagnosis, management of pain and dysfunction of the masticatory system and related structures, as well as development of the clinicians' skill in order to provide quality treatment for patients.

\section{CONCLUSION}

The recognition of the specialty in Brazil presents many challenges and hard work, but the perspectives are promising. Given the complexity of Temporomandibular Disorders and Orofacial Pain, it is necessary to emphasize attention on the education and the development of this area. New models should be implemented, surpassing the prevailing mechanistic models of the past and preparing professionals for a broader and comprehensive care. Professionals should be prepared for interaction between the different areas of health and adopt the biopsychosocial model in understanding patients. Based on the results analyzed, we can conclude that the number of scientific works related to temporomandibular disorders increased significantly in recent years in Brazil, as well as the number of specialization courses and the number of specialists.

\section{REFERENCES}

1- Ash MM. Occlusion: reflections on science and clinical reality. J Prosthet Dent. 2003;90:373-84.

2- Attanasio R. The study of temporomandibular disorders and orofacial pain from the perspective of the predoctoral dental curriculum. J Orofac Pain. 2002;16:176-80.

3- Borromeo GL, Trinca J. Understanding of basic concepts of orofacial pain among dental students and a cohort of general dentists. Pain Med. 2012;13:631-9.

4- Coordenação de Aperfeiçoamento de Pessoal de Nível Superior - CAPES. Qual é a diferença entre o mestrado acadêmico e o mestrado profissional? [online]. [cited Jan. 01 2014]. Available from: http://www.capes.gov.br/duvidas-frequentes/62pos-graduacao/2376-qual-e-a-diferenca-entre-o-mestradoacademico-e-o-mestrado-profissional.

5- Gonzalez YM, MohI ND. Care of patients with temporomandibular disorders: an educational challenge. J Orofac Pain. 2002;16:200-6.
6- Heir GM, Haddox JD, Crandall J, Eliav E, Radford S, Schwartz A, et al. Position paper: appropriate use of pharmacotherapeutic agents by the orofacial pain dentist. J Orofac Pain. 2011;25:38190.

7- Holmes DC, Diaz-Arnold AM, Williams VD. Alumni self-perception of competence at time of dental school graduation. J Dent Educ. 1997;61:465-72.

8- Klasser GD, Gremillion HA. Past, present, and future of predoctoral dental education in orofacial pain and TMDs: a call for interprofessional education. J Dent Educ. 2013;77:395-400 9- Lee WY, Choi JW, Lee JW. A study of dentists' knowledge and beliefs regarding temporomandibular disorders in Korea. Cranio. 2000;18:142-6.

10- Machado LP, Nery CG, Leles CR, Nery MB, Okeson JP. The prevalence of clinical diagnostic groups in patients with temporomandibular disorders. Cranio. 2009;27:194-9.

11- McNeill C, Falace D, Attanasio R. Continuing education for TMD and orofacial pain: a philosophical overview. J Craniomandib Disord. 1992;6:135-6.

12- McNeill C, MohI ND, Rugh JD, Tanaka TT. Temporomandibular disorders: diagnosis, management, education, and research. J Am Dent Assoc. 1990;120:253,255,257.

13- Mohl ND, Attanasio R. The Third Educational Conference to Develop the Curriculum in Temporomandibular Disorders and Orofacial Pain: introduction. J Orofac Pain. 2002;16:173-5.

14- Nilner M, Educational Committee, European Academy of Craniomandibular Disorders. Curriculum guidelines for orofacial pain and temporomandibular disorders. European Academy of Craniomandibular Disorders. Eur J Dent Educ. 2001;5:136-8.

15- Nilner M, Steenks M, De Boever J, Ciancaglini R, Kononen M, Orthlieb JD, et al. Guidelines for curriculum of undergraduate and postgraduate education in orofacial pain and temporomandibular disorders in Europe. J Orofac Pain. 2003;17:359-62.

16- Racich MJ. Orofacial pain and occlusion: is there a link? An overview of current concepts and the clinical implications. J Prosthet Dent. 2005;93:189-96.

17- Santos SM, Lima LS, Martelli DR, Martelli Junior H. Profile of public Health Researchers in the National Council for Scientific and Technological Development. Physis. 2009;19:761-75.

18- Talley RL, Fricton JR, Okeson JP. Broad support evident for the emerging specialty of orofacial pain. J Okla Dent Assoc. 2000;91:14-7.

19- Tegelberg A, List T, Wahlund K, Wenneberg B. Temporomandibular disorders in children and adolescents: a survey of dentists' attitudes, routine and experience. Swed Dent J. $2001 ; 25: 119-27$.

20- Volpato GL, Freitas EG. Challenge in scientific publication. Pesqui Odontol Bras. 2003;17:49-56. 